\title{
Efficacy and safety of perioperative tranexamic acid in elderly patients undergoing trochanteric fracture surgery: a randomised controlled trial
}

\author{
F Chen, Z Jiang, M Li, X Zhu *
}

This article was published on $28 \mathrm{Mar}$ 2019 at www.hkmj.org.

\begin{abstract}
A B S T R A C T
Introduction: Trochanteric fractures result in a high frequency of considerable blood loss, a high incidence of blood transfusions, and a high risk of perioperative morbidity and mortality in elderly patients. This study aimed to evaluate the efficacy and safety of a three-dose regimen of tranexamic acid on blood loss and transfusion rate in elderly patients with trochanteric fractures.
\end{abstract}

Methods: Eligible patients with trochanteric fractures surgically treated by dynamic hip screw and proximal anti-rotating intramedullary nail between March 2016 and October 2017 were enrolled in the study. Patients were randomly assigned to receive $15 \mathrm{mg} / \mathrm{kg}$ intravenous tranexamic acid dissolved in $100 \mathrm{~mL}$ of saline (TXA group) or $100 \mathrm{~mL}$ of saline solution (placebo group) over 10 minutes before, during, and after surgery. Perioperative blood loss, obvious blood loss, and hidden blood loss in the two groups were calculated separately. Vascular events and patient mortality over 6 months' follow-up were noted.

Results: In total, 176 patients were included. Compared with the placebo group $(n=88)$, patients in the TXA group $(\mathrm{n}=88)$ had less blood loss: perioperative blood loss was $205.5 \mathrm{~mL}(\mathrm{P}<0.001)$, obvious blood loss was $125 \mathrm{~mL}(\mathrm{P}<0.001)$, and hidden blood loss was $76.5 \mathrm{~mL}(\mathrm{P}<0.001)$; reduced incidence of blood transfusion ( $17 \%$ vs $35 \%, \mathrm{P}=0.007)$; and shorter hospital stays (median [interquartile range], 7 [6-8] vs 8.5 [7.5-9] days, $\mathrm{P}<0.001)$.

Conclusion: Tranexamic acid significantly lowered perioperative blood loss and blood transfusion rate without an increased risk of venous thromboembolism or mortality in elderly patients with trochanteric fractures treated with dynamic hip screw or proximal anti-rotating intramedullary nail.

\section{Hong Kong Med J 2019;25:120-6 \\ https://doi.org/10.12809/hkmj187570}

F Chen, MD

$Z$ Jiang, MD

$M \mathrm{Li}, \mathrm{MD}$

$X Z$ Zhu *, MD

Department of Anesthesiology, The First Affiliated Hospital of Nanchang University, Jiangxi, China

* Corresponding author: 13907915506@163.com

New knowledge added by this study

- A three-dose regimen of tranexamic acid in elderly patients with trochanteric fractures treated with dynamic hip screw or proximal anti-rotating intramedullary nail significantly reduced perioperative blood loss and the transfusion rate.

- The three-dose regimen of tranexamic acid did not increase the risk of venous thromboembolism or mortality in patients.

Implications for clinical practice or policy

- This study will help surgeons to reduce blood loss and transfusion during surgery in patients with trochanteric fractures.

\section{Introduction}

The increasing number of elderly people with osteoporosis is bringing about an increased incidence of trochanteric fractures, which include intertrochanteric fractures and subtrochanteric fractures. This common type of fractures frequently results in considerable blood loss, ${ }^{1}$ which exposes patients to postoperative anaemia and reduced functional recovery. ${ }^{2}$ Further, large amounts of blood loss usually result in blood transfusion and a high risk of perioperative morbidity and mortality. ${ }^{3}$ Blood transfusion increases the incidence of adverse reactions related to allogeneic blood transfusion, such as infectious diseases, haemolytic reaction, cardiovascular dysfunction, postoperative infection, ${ }^{4-7}$ and elevated hospitalisation costs. ${ }^{8,9}$ Postoperative mortality rates have been reported as high as $10 \%$ at 30 days and $30 \%$ at 1 year. ${ }^{10}$ Therefore, reducing perioperative blood loss concomitant to trochanteric fractures in elderly patients would help to decrease the rate of complications and improve surgical outcomes.

Tranexamic acid (TXA), a synthetic derivative of the amino acid lysine, is an antifibrinolytic drug that competitively blocks the plasminogen-binding site, inhibits plasminogen activation, and interferes 
with fibrinolysis. ${ }^{11}$ Currently, TXA is widely used in clinical surgery. Numerous studies have indicated that intravenous TXA reduces blood loss and transfusion rates without increasing thrombotic events in joint arthroplasty. ${ }^{12-14}$ Similar results have been found in surgical patients undergoing treatment for trauma, including decreased mortality due to haemorrhage. ${ }^{15}$ However, studies have also shown that TXA, as compared with placebo, not only offers no significant benefit regarding transfusion rate, estimated blood loss, and incidence of deep venous thrombosis in patients undergoing open reduction and internal fixation with acetabular fracture, ${ }^{16}$ but also increases the formation of deep vein thrombosis after hip fracture in elderly patients. ${ }^{17}$ Thus, the efficacy and safety of TXA in the perioperative period of hip fracture in elderly patients remain controversial.

In the present study, we evaluated the effects of TXA administration in elderly patients undergoing surgery for trochanteric fracture. Specifically, we aimed to evaluate whether a three-dose regimen of TXA decreases perioperative blood loss and the incidence of allogenic blood transfusion without increasing the risk of venous thromboembolism and mortality.

\section{Methods}

\section{Patients and methods}

To clarify the effects of TXA in surgical treatment of trochanteric fractures in elderly patients, a placebocontrolled double-blind randomised clinical trial was performed in our hospital in accordance with the provisions of the Declaration of Helsinki, as revised in 2013. ${ }^{18}$

Elderly patients with trochanteric fractures who were treated with dynamic hip screw (DHS) and proximal anti-rotating intramedullary nail (PFNA) in our hospital between March 2016 and October 2017 were included in this study. Patients eligible for inclusion had American Society of Anesthesiologists (ASA) scores of II (mild systemic disease that results in no functional limitation) or III (serious systemic disease that results in functional impairment), were aged $\geq 65$ years, and were treated with either DHS or PFNA within 48 hours after injury. Exclusion criteria were as follows: (1) allergy to TXA or low-molecularweight heparin; (2) severe dysfunction of heart, lung, liver, kidney, or coagulation; (3) provoked deep venous thrombosis or pulmonary embolism within 30 days or myocardial infarction, cerebrovascular accident, or stent placement within 6 months; (4) anticoagulant therapy such as antiplatelet drugs or warfarin before surgery; (5) multiple fractures; and (6) blood transfusion before surgery.

All patients underwent preoperative medical optimisation by a hospitalist medicine team. All

\section{華氨甲環酸在老年患者粗隆間骨折手術應用的 安全有效性：一項隨機對照試驗 \\ 陳福梅、蔣章頡、李夢園、朱小萍}

引言：粗隆間骨折可導致大量失血、輸血率高, 以及老年患者高風險 的圍手術期發病和死亡率。本研究旨在評估三劑量氨甲環酸對老年股 骨粗隆間骨折患者失血和輸血率的療效和安全性。

方法：2016年3月至2017年10月期間，採用動力髖螺釘和近端防旋 髓內釬手術治療的合資格粗隆間骨折患者被納入研究。患者在手術 前、手術中和手術後隨機分配接受溶於 $100 \mathrm{~mL}$ 生理鹽水 (TXA組) 或 $100 \mathrm{~mL}$ 生理鹽水 (安慰劑組) 的 $15 \mathrm{mg} / \mathrm{kg}$ 靜脈注射氨甲環酸多於 10 分鐘。分別計算兩組圍手術期出血量、明顯失血量和隱性失血量, 以 及6個月隨訪期內的血管事件和患者死亡率。

結果：共納入 176 名患者。與安慰組 $(n=88)$ 相比, TXA組 $(n=88)$ 出血量較少：圍手術期出血量為 $205.5 \mathrm{~mL}(\mathrm{P}<0.001)$, 明顯失血量 為 $125 \mathrm{~mL}(\mathrm{P}<0.001)$, 隱性失血量為76.5 mL $(\mathrm{P}<0.001)$; 輸血 發生率下降 $(17 \%$ 比 $35 \%, \mathrm{P}=0.007)$ 及住院時間較短（中位數 [四分 位數 $], 7$ [6-8] 天比8.5 [7.5-9] 天, $\mathrm{P}<0.001$ )

結論：以動力髖螺釘或近端防旋髓內釘治療粗隆間骨折老年患者時使 用氨甲環酸可顯著減低圍手術期出血量和輸血率, 亦沒有增加靜脈血 栓栓塞或死亡的風險。

patients received spinal or general anaesthesia without regional blockade or local injection. Patients were assigned at random to receive TXA treatment (TXA group) or placebo control (placebo group). Patients in the TXA group received three doses of $15 \mathrm{mg} / \mathrm{kg}$ intravenous TXA dissolved in $100 \mathrm{~mL}$ of saline. Each of the doses was administered over 10 minutes: the first dose was used within 10 minutes just before incision, the second continuously pumped throughout the entire surgery, and the third was used at 3 hours after surgery (three-dose regimen). ${ }^{19}$ In the placebo group, $100 \mathrm{~mL}$ of saline solution was administered following the same three-dose regimen. During the surgery, crystalloid maintenance fluids were administered at a rate of $1.5 \mathrm{~mL} / \mathrm{kg}$ per hour. Blood losses were replaced with Ringer's lactate in a 3:1 ratio, colloidal solution (or $5 \%$ albumin) in a 1:1 ratio, or a combination (crystalloid/colloidal ratio, 2:1) until the haemoglobin (Hb) concentration fell below the transfusion trigger point. Changes of $20 \%$ in baseline heart rate or blood pressure due to hypovolaemia were managed with boluses of 10 $\mathrm{mL} / \mathrm{kg}$ crystalloid solution or $500 \mathrm{~mL}$ of colloidal solution (5\% albumin).

Perioperative transfusion was based on the Chinese "Measures for the management of clinical blood use in medical institutions" guideline..$^{20}$ Intra-operative allogenic blood transfusion was administered for all patients who had Hb levels $<7.0$ $\mathrm{g} / \mathrm{dL}$ and those with Hb levels $<10 \mathrm{~g} / \mathrm{dL}$ also suspected to have myocardial ischaemia or haemorrhagic 
shock. Postoperative blood transfusion was based on arterial blood gas analysis and routine blood examination. When a patient receives a blood transfusion, an arterial blood gas analysis should be performed after each infusion of 1 unit of red blood cells to reassess whether to continue the transfusion.

All patients received deep venous thrombosis prophylaxis including sequential compression devices throughout hospitalisation and prophylactic low-molecular-weight heparin for 30 days after surgery beginning on postoperative day (POD) 1 unless therapeutic anticoagulation was contraindicated because of pre-existing co-morbidities or postoperative complications.

\section{Sample size}

The perioperative transfusion rate of trochanteric fractures was $34 \%$ at our institution. Assuming that a similar rate of transfusion would be observed in the control subjects, our sample size was calculated to be able to detect a difference of $34 \%$ with respect to $10 \%$ (a risk reduction of approximately $1 / 3$ of the baseline rate) between the TXA and placebo groups. We then calculated that a sample of 88 participants per study group would provide $90 \%$ power to detect such a difference ( $\alpha=0.05$, two-sided test).

\section{Randomisation and blinding}

Participants were randomised into either the TXA group or the placebo group using a computerised dynamic allocation programme and stratification according to sex (male or female), age $(<75$ or $\geq 75$ years), and type of surgery (DHS or PFNA) by means of a central telephone system with a computergenerated randomisation list to ensure that subject allocation remained balanced throughout the entire subject accrual phase. All operations were performed by the same orthopaedic surgeons, who determined the type of surgery. All investigational drugs were administered by a nurse during preoperative preparation and then delivered to the operating room in packaging simply labelled as "study drug". To ensure that subjects, physicians, and data collectors were blinded, the patient caregivers, investigators collecting the data, safety monitoring board, and members of the adjudication committee remained unaware of the study group assignments.

\section{Outcomes}

Patient characteristics including sex, age, body mass index, ASA score, preoperative $\mathrm{Hb}$ concentration, proportions of preoperative hypertension and diabetes, surgery type, time from injury to surgery, surgical duration, and length of hospital stay were recorded.

All patient outcomes were assessed by the independent adjudication committee. The primary outcomes included perioperative blood loss and proportion of patients receiving blood transfusion from the beginning of surgery to discharge. Secondary outcomes including obvious blood loss; hidden blood loss; postoperative $\mathrm{Hb}$ concentration of POD 1, POD 2, and POD 3; number of units of transfusion during hospitalisation; and incidence of adverse events at 6-month follow-up (including thromboembolic events, wound complications, and mortality) were identified. Investigation for thromboembolic events, defined as symptomatic deep venous thrombosis, pulmonary embolism, myocardial infarction, and cerebrovascular accident diagnosed by duplex ultrasound, was only performed in patients with acute symptoms. Diagnosis of pulmonary embolism was performed using contrast chest computed tomography. Myocardial infarction was diagnosed using electrocardiography and cardiac enzymes. Confirmation of cerebrovascular accident was done by brain computed tomography or magnetic resonance imaging. Wound complications were defined to include haematoma and deep or superficial infection. The patients' medical history was asked before surgery. If the patient had any symptoms associated with thromboembolic events, tests were given to him/her.

\section{Calculation methods}

Patient blood volume was calculated using the formula of Nadler et al, ${ }^{21}$ as follows: blood volume $=\left(\mathrm{k} 1 \times\right.$ height $\left.^{3}[\mathrm{~m}]\right)+(\mathrm{k} 2 \times$ weight $[\mathrm{kg}])+\mathrm{k} 3$, where $\mathrm{k} 1=0.3669, \mathrm{k} 2=0.03219$, and $\mathrm{k} 3=0.6041$ for men and $\mathrm{k} 1=0.3561, \mathrm{k} 2=0.03308$, and $\mathrm{k} 3=0.1833$ for women.

The Gross equation was used to calculate the total red blood cell volume loss, ${ }^{22}$ as follows: total red blood cell volume loss $=$ patient blood volume $\times$ (preoperative haematocrit - postoperative haematocrit), where preoperative haematocrit is the haematocrit on the morning of the day of surgery, and postoperative haematocrit is the haematocrit on POD 2. Haematocrit was chosen for investigation because it is directly correlated with blood volume.

Theoretical blood loss refers to the total red blood cell volume loss / preoperative haematocrit. Perioperative blood loss refers to hidden blood loss + obvious blood loss (surgical blood loss + postoperative drainage), or theoretical blood loss + blood transfusion volume. Hidden blood loss refers to the amount of theoretical blood loss and blood transfusion volume, minus obvious blood loss.

\section{Statistical methods}

Data were analysed using SPSS (Windows version 24.0; IBM Corp, Armonk [NY], United States). Descriptive data assumed to follow normal distributions were expressed as mean \pm standard 
deviation, and comparisons of descriptive data for completely random distributions were conducted with two independent-samples $t$ tests. The measurement data of skewed distributions were represented by median (interquartile range; IQR) and compared with non-parametric Wilcoxon rank sum tests between two independent samples. Categorical data were checked by Chi squared tests. Baseline covariates were evaluated to ensure consistency between groups. All statistical tests were two-sided, and the threshold of statistical significance was set at $\alpha=0.05$.

\section{Results}

A total of 176 patients were included in this study (88 patients in each group). All patients were followed up for 6 months. There were no statistically significant differences between the TXA and placebo groups in terms of patients' sex, age, body mass index, ASA scores, proportion of preoperative hypertension and diabetes, or preoperative $\mathrm{Hb}$ concentration. The TXA group had shorter median (IQR) hospital stays than the placebo group (7 [6-8] vs 8.5 [7.5-9] days; $\mathrm{P}<0.001)$. Furthermore, a similar number of patients underwent DHS and PFNA in each group, and no differences were detected in terms of time to surgery or operating time between the two groups (Table 1).

The postoperative $\mathrm{Hb}$ levels at POD 1, POD 2, and POD 3 were higher in the TXA group than in the placebo group, there were statistically significant differences on POD 1 (10.9 vs $10.3 \mathrm{~g} / \mathrm{dL}, \mathrm{P}=0.004$ ) and POD 2 (9.8 vs $9.3 \mathrm{~g} / \mathrm{dL}, \mathrm{P}=0.028)$, but no statistically significant differences on POD 3 (9.5 vs $9.1 \mathrm{~g} / \mathrm{dL}, \mathrm{P}=0.057$ ) [Table 2].

Mean perioperative blood loss in the TXA group was $205.5 \mathrm{~mL}$ lower than that in the placebo group (411 vs $616.5 \mathrm{~mL}, \mathrm{P}<0.01$ ). Obvious blood loss was $125 \mathrm{~mL}$ lower in the TXA group than in the placebo group (142 vs $267 \mathrm{~mL}, \mathrm{P}<0.01)$, and hidden blood loss was $76.5 \mathrm{~mL}$ lower in the TXA group than in the placebo group (266 vs $342.5 \mathrm{~mL}, \mathrm{P}<0.01$ ) [Table 2].

Fewer patients in the TXA group than the placebo group received allogenic blood transfusions ( $17 \%$ vs $35 \%, \mathrm{P}=0.007$ ). Furthermore, patients with TXA tended to require less total blood product (median 1.5 units packed red blood cells/patient; IQR, 1-2 units) than those in the placebo group did (median 2.5 units packed red blood cells/patient; IQR, 1.5-3.5 units; $\mathrm{P}<0.01$ ) [Table 2].

After surgery, three patients were lost to followup in the TXA group and two were lost to follow-

TABLE I. Baseline demographics and characteristics of the two patient groups*

\begin{tabular}{|c|c|c|c|}
\hline & TXA group $(n=88)$ & Placebo group $(n=88)$ & $P$ value \\
\hline Sex & & & $0.761 \dagger$ \\
\hline Male & $39(44 \%)$ & $37(42 \%)$ & \\
\hline Female & $49(56 \%)$ & $51(58 \%)$ & \\
\hline Age (years) & $76.8 \pm 7.0$ & $77.4 \pm 6.8$ & $0.319 \ddagger$ \\
\hline Body mass index $\left(\mathrm{kg} / \mathrm{m}^{2}\right)$ & $21.73 \pm 2.09$ & $21.74 \pm 2.14$ & $0.969 \ddagger$ \\
\hline ASA score & & & $0.651 \dagger$ \\
\hline II & $42(48 \%)$ & $45(51 \%)$ & \\
\hline III & $46(52 \%)$ & $43(49 \%)$ & \\
\hline Hypertension ratio & $36(41 \%)$ & $37(42 \%)$ & $0.878 \dagger$ \\
\hline Diabetes ratio & $21(24 \%)$ & $19(22 \%)$ & $0.719 \dagger$ \\
\hline Preoperative $\mathrm{Hb}(\mathrm{g} / \mathrm{dL})$ & $11.68 \pm 1.34$ & $11.73 \pm 1.35$ & $0.810 \ddagger$ \\
\hline Time from injury to surgery (hours) & $35.18 \pm 3.87$ & $36.09 \pm 4.66$ & $0.176 \ddagger$ \\
\hline Type of surgery & & & $0.521 \dagger$ \\
\hline DHS & $27(31 \%)$ & $31(35 \%)$ & \\
\hline PFNA & $61(69 \%)$ & $57(65 \%)$ & \\
\hline Operating time (minutes) & $44.12 \pm 4.90$ & $45.00 \pm 4.75$ & $0.626 \ddagger$ \\
\hline Hospital stay (days) & $7(6-8)$ & $8.5(7.5-9)$ & $<0.001 \S$ \\
\hline
\end{tabular}

Abbreviations: $\mathrm{ASA}=$ American Society of Anesthesiologists; $\mathrm{DHS}=$ dynamic hip screw; $\mathrm{Hb}=$ haemoglobin; $\mathrm{PFNA}=$ proximal antirotating intramedullary nail;TXA = tranexamic acid

* Data are shown as No. (\%) of patients, mean \pm standard deviation, or median (interquartile range)

+ Chi squared test

$\ddagger$ Independent-samples $t$ test

$\S$ Wilcoxon test 
up in the placebo group. In the TXA group, five (5.9\%) patients had wound complications, including three (3.5\%) with haematoma and two $(2.4 \%)$ with infection. The incidence of thromboembolic events was $16.5 \%$ in the TXA group, including $10(11.8 \%)$ patients with deep venous thrombosis and two $(2.4 \%)$ each with pulmonary embolism and cerebrovascular accident. Five patients died: the mortality rate in the TXA group was $5.9 \%$. In the placebo group, wound complications occurred in eight $(9.3 \%)$ cases, including five $(5.8 \%)$ with haematoma and three (3.5\%) with infection. We observed thromboembolic events in 12 (14.0\%) cases, including $11(12.8 \%)$ cases with deep venous thrombosis and one $(1.2 \%)$

TABLE 2. Comparison between the two patient groups in terms of postoperative $\mathrm{Hb}$, blood loss, packed RBC transfusion, and units of packed RBC transferred per patient

\begin{tabular}{lccr}
\hline & $\begin{array}{c}\text { TXA group } \\
(\mathbf{n}=\mathbf{8 8})\end{array}$ & $\begin{array}{c}\text { Placebo group } \\
(\mathbf{n}=\mathbf{8 8})\end{array}$ & P value \\
\hline Postoperative Hb (g/dL) & & & \\
\hline POD 1 & $10.9 \pm 0.53$ & $10.3 \pm 0.67$ & $0.004 \ddagger$ \\
\hline POD 2 & $9.8 \pm 0.57$ & $9.3 \pm 0.67$ & $0.028 \ddagger$ \\
\hline POD 3 & $9.5 \pm 0.52$ & $9.1 \pm 0.56$ & $0.057 \ddagger$ \\
\hline Perioperative blood loss $(\mathrm{mL})$ & $411 \pm 108.8$ & $616.5 \pm 106.3$ & $<0.001 \S$ \\
\hline Obvious blood loss $(\mathrm{mL})$ & $142 \pm 60.5$ & $267 \pm 50.8$ & $<0.001 \S$ \\
\hline Hidden blood loss $(\mathrm{mL})$ & $266 \pm 56.5$ & $342.5 \pm 81$ & $<0.001 \S$ \\
\hline Packed RBC transfusion & $15(17 \%)$ & $31(35 \%)$ & $0.007 \dagger$ \\
\hline $\begin{array}{l}\text { No. of units of packed RBCs } \\
\text { per patient transfused }\end{array}$ & $1.5(1-2)$ & $2.5(1.5-3.5)$ & $<0.001 \S$ \\
\hline
\end{tabular}

Abbreviations: $\mathrm{Hb}=$ haemoglobin; $\mathrm{POD}=$ postoperative day; $\mathrm{RBC}=$ red blood cell; TXA = tranexamic acid

* Data are shown as No. (\%) of patients, median (interquartile range), or mean \pm standard deviation

+ Chi squared test

$\ddagger$ Independent-samples $t$ test

$\S$ Wilcoxon test

TABLE 3. Postoperative follow-up outcomes of the two patient groups*

\begin{tabular}{lccc}
\hline Outcome & TXA group $(\mathbf{n = 8 5 )}$ & $\begin{array}{c}\text { Placebo group } \\
(\mathbf{n = 8 6 )}\end{array}$ & P value \\
\hline Wound complications & $5(5.9 \%)$ & $8(9.3 \%)$ & $0.399^{\star}$ \\
\hline Haematoma & $3(3.5 \%)$ & $5(5.8 \%)$ & $0.730 \dagger$ \\
\hline Infection & $2(2.4 \%)$ & $3(3.5 \%)$ & $1.000 \dagger$ \\
\hline Thromboembolic events & $14(16.5 \%)$ & $12(14.0 \%)$ & $0.647^{\star}$ \\
\hline \multicolumn{1}{c}{ Deep vein thrombosis } & $10(11.8 \%)$ & $11(12.8 \%)$ & $0.838^{*}$ \\
\hline Pulmonary embolism & $2(2.4 \%)$ & $1(1.2 \%)$ & $0.992 \dagger$ \\
\hline Myocardial infarction & 0 & 0 & - \\
\hline Cerebrovascular accident & $2(2.4 \%)$ & 0 & $0.246 \ddagger$ \\
\hline Death & $5(5.9 \%)$ & $3(3.5 \%)$ & $0.705 \dagger$ \\
\hline
\end{tabular}

Abbreviation:TXA = tranexamic acid

* Chi squared test

+ Chi squared test with continuity correction

$\neq$ Fisher's exact test with pulmonary embolism. Three patients died: the mortality rate in the placebo group was $3.5 \%$. There were no statistically significant differences between the two groups in wound complications, thromboembolic events, or death [Table 3].

\section{Discussion}

Trochanteric fractures caused by osteoporosis have become common. Trochanteric fractures account for a large number of hospital days, much blood loss, and high mortality. ${ }^{23}$ With a mortality rate of up to $30 \%$ in the year after injury, these patients are among the most frail that orthopaedic surgeons treat. ${ }^{24}$ Although TXA is known to be an effective and safe agent for reducing surgical blood loss, ${ }^{25-27}$ with improved perioperative care for patients undergoing hip arthroplasty, ${ }^{28}$ there are limited data regarding its use in trochanteric fracture surgery. ${ }^{17}$ Therefore, in the present study, we sought to determine whether intravenous TXA administration would improve perioperative blood management without increasing levels of adverse complications.

The mean rate of transfusion (26.1\%) and mean estimated blood loss $(567 \mathrm{~mL})$ in the current study are similar to those in previous reports about surgical treatment of trochanteric fractures (DHS or PFNA). ${ }^{29,30}$ Older patients have lower preoperative $\mathrm{Hb}$ values, and older age and intramedullary nail osteosynthesis both increase the risk of erythrocyte transfusion. ${ }^{17}$ This study design accounted for this major confounder through stratification of randomisation by age.

The dosage and timing of TXA administration in our study were selected in accordance with Maniar et $\mathrm{al}^{19}$ which indicated that the three-dose regimen produces maximum effective reduction of drainage loss and total blood loss. The present findings suggest that the three-dose regimen could significantly reduce blood loss and decrease the rate of transfusion without increasing the risk of the postoperative complications of thromboembolic events and mortality. We will further study the effects of different TXA administration regimens on perioperative blood loss and blood transfusion rate in elderly patients with hip fracture.

Blood conservation is particularly important in patients with trochanteric fracture to prevent complications related to acute postoperative anaemia. The three-dose regimen of TXA has been reported to decrease blood loss in patients undergoing hip fracture surgery. ${ }^{31,32}$ In the present study, a significant reduction in the incidence of transfusion (17\% vs $35 \%$ ), perioperative blood loss, obvious blood loss, and hidden blood loss were found (Table 2) with TXA administration in trochanteric fracture surgery. These results are consistent with those of previous studies. $^{33,34}$ Gausden et $\mathrm{al}^{35}$ and Schiavone et $\mathrm{al}^{36}$ reported significant reductions in transfusion rates 
with TXA use versus placebo. In the TXA in Hip Fracture Surgery study, Zufferey et $\mathrm{al}^{17}$ also reported the same trend with a $30 \%$ relative reduction in transfusion rates with TXA administration. Thus, our findings suggest that TXA has clear benefits in DHS or PFNA of trochanteric fractures.

Despite the wide use of TXA, there has been concern regarding its association with increased incidence of venous thrombosis and mortality. ${ }^{32}$ Zufferey et $\mathrm{al}^{17}$ and Schiavone et $\mathrm{al}^{36}$ reported a three-fold increase in vascular events (deep venous thrombosis, pulmonary embolism, cerebrovascular accident, and myocardial infarction) with intravenous TXA administration in hip fracture surgery, but this was not statistically significant. A number of metaanalyses have found no increase in thromboembolic complications but were unable to draw conclusions regarding the safety of TXA because of potential bias. ${ }^{26,27}$ A recent population-based study conducted by Poeran et $\mathrm{al}^{37}$ involving 872416 patients showed no increase in thromboembolic events. In our study, no statistically significant differences were found between the TXA and placebo groups for incidence of wound complications, thromboembolic events, or mortality after 6 months' follow-up (Table 3). Our results were in accordance with the systematic reviews of Farrow et $\mathrm{al}^{38}$ and Zhang et $\mathrm{al}^{33}$ which indicated that TXA did not increase the risk of wound complications, thromboembolic events, or mortality.

In our study, the length of hospital stay in the TXA group was less than that in the placebo group. The reasons may be that, first, TXA administration can reduce perioperative blood loss and then prevent postoperative anaemia in patients; second, TXA may decrease the risk associated with transfusion by reducing the rate of transfusion. Minimising blood loss and red blood cell transfusion can enable early activity, enhance patient rehabilitation, and facilitate early hospital discharge. ${ }^{39}$

This study had some limitations. Although this was a randomised controlled trial, the surgical procedure was decided by the surgeon, which may have affected the outcome. In addition, the proper usage method of TXA is still unclear. Furthermore, the optimal dosing and timing of TXA administration is still controversial. Further study with a larger sample and a multicentre trial would be helpful to verify the present results.

\section{Conclusion}

The results of this study suggest that TXA can reduce perioperative blood loss and decrease the risk associated with transfusion by reducing the rate of transfusion without increasing the incidence of complications of thromboembolic events or mortality in patients with trochanteric fractures. Thus, off-label use of TXA can be recommended for trochanteric fracture surgery. The blood conservational effects of TXA are well established and appear to be safe and effective. In the future, we will conduct a study to clarify the reasonable dosage and timing of TXA in patients with different types of hip fractures.

\section{Author contributions}

All authors had full access to the data, contributed to the study, approved the final version for publication, and take responsibility for its accuracy and integrity.

Concept or design of study: X Zhu.

Acquisition of data: Z Jiang, M Li.

Analysis or interpretation of data: F Chen.

Drafting of the manuscript: F Chen.

Critical revision for important intellectual content: F Chen.

\section{Conflicts of interest}

The authors have no conflicts of interests to disclose.

\section{Funding/support}

This research received no specific grant from any funding agency in the public, commercial, or not-for-profit sectors.

\section{Ethics approval}

Approval was obtained from our institution's internal ethics committee (No. 2016-01-025). Written informed consent was obtained from all patients or a legally authorised representative.

\section{References}

1. Foss NB, Kehlet H. Hidden blood loss after surgery for hip fracture. J Bone Joint Surg Br 2006;88:1053-9.

2. Lawrence VA, Silverstein JH, Cornell JE, Pederson T, Noveck H, Carson JL. Higher Hb level is associated with better early functional recovery after hip fracture repair. Transfusion 2003;43:1717-22.

3. Maxwell L, White S. Anaesthetic management of patients with hip fractures: an update. Contin Educ Anaesth Crit Care Pain 2013;13:179-83.

4. Vamvakas EC, Blajchman MA. Transfusion-related mortality: the ongoing risks of allogeneic blood transfusion and the available strategies for their prevention. Blood 2009;113:3406-17.

5. Newman ET, Watters TS, Lewis JS, et al. Impact of perioperative allogeneic and autologous blood transfusion on acute wound infection following total knee and total hip arthroplasty. J Bone Joint Surg Am 2014;96:279-84.

6. Carson JL, Altman DG, Duff A, et al. Risk of bacterial infection associated with allogeneic blood transfusion among patients undergoing hip fracture repair. Transfusion 1999;39:694-700.

7. Allain JP, Stramer SL, Carneiro-Proietti AB, et al. Transfusion-transmitted infectious diseases. Biologicals 2009;37:71-7.

8. Klein HG, Spahn DR, Carson JL. Red blood cell transfusion in clinical practice. Lancet 2007;370:415-26.

9. Carson JL, Terrin ML, Noveck $\mathrm{H}$, et al. Liberal or restrictive transfusion in high-risk patients after hip surgery. New Engl J Med 2011;365:2453-62. 
10. National Clinical Guideline Centre. NICE clinical guidelines No. 124: the management of hip fracture in adults. London, United Kingdom: Royal College of Physicians; 2011: 68-81.

11. Astedt B, Liedholm P, Wingerup L. The effect of tranexamic acid on the fibrinolytic activity of vein walls. Ann Chir Gynaecol 1978;67:203-5.

12. Chen Y, Chen Z, Cui S, Li Z, Yuan Z. Topical versus systemic tranexamic acid after total knee and hip arthroplasty: a meta-analysis of randomized controlled trials. Medicine (Baltimore) 2016;95:e4656

13. Ueno M, Sonohata M, Fukumori N, Kawano S, Kitajima M, Mawatari M. Comparison between topical and intravenous administration of tranexamic acid in primary total hip arthroplasty. J Orthop Sci 2016;21:44-7.

14. North WT, Mehran N, Davis JJ, Silverton CD, Weir RM, Laker MW. Topical vs intravenous tranexamic acid in primary total hip arthroplasty: a double-blind, randomized controlled trial. J Arthroplasty 2016;31:1022-6.

15. CRASH-2 Trial Collaborators, Shakur H, Roberts I, et al. Effects of tranexamic acid on death, vascular occlusive events, and blood transfusion in trauma patients with significant haemorrhage (CRASH-2): a randomised, placebo-controlled trial. Lancet 2010;376:23-32.

16. Lack WD, Crist BD, Seymour RB, Harvin W, Karunakar MA, TXA Study Group II. Effect of tranexamic acid on transfusion: a randomized clinical trial in acetabular fracture surgery. J Orthop Trauma 2017;31:526-30.

17. Zufferey PJ, Miquet M, Quenet S, et al. Tranexamic acid in hip fracture surgery: a randomized controlled trial. $\mathrm{Br}$ ) Anaesth 2010;104:23-30.

18. World Medical Association. World Medical Association Declaration of Helsinki: ethical principles for medical research involving human subjects. JAMA 2013;310:21914.

19. Maniar RN, Kumar G, Singhi T, Nayak RM, Maniar PR. Most effective regimen of tranexamic acid in knee arthroplasty: a prospective randomized controlled study in 240 patients. Clin Orthop Relat Res 2012;470:2605-12.

20. Ministry of Public Health of China. Measures for the management of clinical blood use in medical institutions. China Med Pharm 2012;02:6-8.

21. Nadler SB, Hidalgo JH, Bloch T. Prediction of blood volume in normal human adults. Surgery 1962;51:224-32.

22. Gross JB. Estimating allowable blood loss: corrected for dilution. Anesthesiology 1983;58:277-80.

23. Dhanwal DK, Dennison EM, Harvey NC, Cooper C. Epidemiology of hip fracture: worldwide geographic variation. Indian J Orthop 2011;45:15-22.

24. Moran CG, Wenn RT, Sikand M, Taylor AM. Early mortality after hip fracture: is delay before surgery important? J Bone Joint Surg Am 2005;87:483-9.

25. McCormack PL. Tranexamic acid: a review of its use in the treatment of hyperfibrinolysis. Drugs 2012;72:585-617.

26. Ker K, Edwards P, Perel P, Shakur H, Roberts I. Effect of tranexamic acid on surgical bleeding: systematic review and cumulative meta-analysis. BMJ 2012;344:e3054.

27. Huang F, Wu D, Ma G, Yin Z, Wang Q. The use of tranexamic acid to reduce blood loss and transfusion in major orthopedic surgery: a meta-analysis. J Surg Res 2014;186:318-27.

28. Watts CD, Pagnano MW. Minimising blood loss and transfusion in contemporary hip and knee arthroplasty. J Bone Joint Surg Br 2012;94(11 Suppl A):8-10.

29. Lei JL, Zhang B, Cong Y, et al. Tranexamic acid reduces hidden blood loss in the treatment of intertrochanteric fractures with PFNA: a single-center randomized controlled trial. J Orthop Surg Res 2017;12:124.

30. Tian S, Shen Z, Liu Y, Zhang Y, Peng A. The effect of tranexamic acid on hidden bleeding in older intertrochanteric fracture patients treated with PFNA. Injury 2018;49:680-4.

31. Lee C, Freeman R, Edmondson M, Rogers BA. The efficacy of tranexamic acid in hip hemiarthroplasty surgery: an observational cohort study. Injury 2015;46:1978-82.

32. Tengberg PT, Foss NB, Palm H, Kallemose T, Troelsen A. Tranexamic acid reduces blood loss in patients with extracapsular fractures of the hip: results of a randomised controlled trial. Bone Joint J 2016;98B:747-53.

33. Zhang P, He J, Fang Y, Chen P, Liang Y, Wang J. Efficacy and safety of intravenous tranexamic acid administration in patients undergoing hip fracture surgery for hemostasis: A meta-analysis. Medicine (Baltimore) 2017;96:e6940.

34. Wingerter SA, Keith AD, Schoenecker PL, Baca GR, Clohisy JC. Does tranexamic acid reduce blood loss and transfusion requirements associated with the periacetabular osteotomy? Clin Orthop Relat Res 2015;473:2639-43.

35. Gausden EB, Garner MR, Warner SJ, et al. Tranexamic acid in hip fracture patients: a protocol for a randomised, placebo controlled trial on the efficacy of tranexamic acid in reducing blood loss in hip fracture patients. BMJ Open 2016;6:e10676.

36. Schiavone A, Bisaccia M, Inkov I, et al. Tranexamic acid in pertrochanteric femoral fracture: is it a safe drug or not? Folia Med (Plovdiv) 2018;60:67-78.

37. Poeran J, Rasul R, Suzuki S, et al. Tranexamic acid use and postoperative outcomes in patients undergoing total hip or knee arthroplasty in the United States: retrospective analysis of effectiveness and safety. BMJ 2014;349:g4829.

38. Farrow LS, Smith TO, Ashcroft GP, Myint PK. A systematic review of tranexamic acid in hip fracture surgery. $\mathrm{Br} J$ Clin Pharmacol 2016;82:1458-70.

39. Willems JM, de Craen AJ, Nelissen RG, van Luijt PA, Westendorp RG, Blauw GJ. Haemoglobin predicts length of hospital stay after hip fracture surgery in older patients. Maturitas 2012;72:225-8. 